\title{
Spontaneous motility of the oviduct in the anaesthetized
}

\author{
H. Rodriguez-Martinez, S. Einarsson and B. Larsson* \\ Department of Obstetrics and Gynaecology, Swedish University of Agricultural Sciences, \\ S-750 07 Uppsala, Sweden
}

\begin{abstract}
Summary. Intraluminal pressure microtransducers were placed at the uterotubal junction, the proximal isthmus, the ampullary-isthmic junction and the mid-ampulla. Spontaneous motility occurred throughout the oestrous cycle in all segments. During oestrus there were regular, high amplitude peristaltic waves in all segments, superimposed on basal activity. On Day 1 of the cycle the pattern was mostly antiperistaltic, presumably related to sperm transport. During the periovulatory period the number of peristaltic and antiperistaltic waves became equal, perhaps in relation to the transport of gametes to the fertilization site. During Day 3 there was no peristaltic activity; the motility patterns of the isthmus and ampullary-isthmic junction were similar (regular phasic contractions of high frequency and amplitude) while the ampullary motility was low. On Day 4, when the eggs enter the uterine lumen, the ampullary-isthmic junction and particularly the isthmus showed strong contraction waves (mostly peristaltic) superimposed on the basal phasic activity. This suggests an active role of the smooth muscle of the lower oviducal segments in ovum descent. During the mid- and late-luteal phases, the isthmus remained motile, with an irregular base line, but lost the pattern of basal contractions that dominated the activity during the first 4 days of the cycle. The ampulla showed low levels of spontaneous motility throughout the rest of the cycle.
\end{abstract}

\section{Introduction}

The porcine oviduct is able to transport spermatozoa and ova in opposite directions at almost the same time (Blandau et al., 1977). Rapid and sequentially phased sperm transport towards the ovarian end of the oviduct (Viring, 1981), as well as a rather slow transport of ova from the ovarian to the uterine end (Alanko, 1974), is known to occur under physiological conditions.

Tubal cilia and secretions are assumed to play a role in gamete and embryo transport in mammals (Blandau et al., 1977) but smooth muscle activity is considered the most important factor for effective sperm transport (Blandau \& Gaddum-Rosse, 1974) and ova descent (RodriguezMartinez, Einarsson, Larsson, Akusu \& Settergren, 1982) in the pig.

The spontaneous motility of pig oviducts has mainly been studied in vitro, using methods of force displacement of longitudinal tubal strips (Einarsson \& Viring, 1973; Borda, Speziale, Borda, Gimeno \& Gimeno, 1980) or a highly sensitive intraluminal pressure microtransducer (RodriguezMartinez et al., 1982). The latter technique gave reliable recordings of intact mesosalpinx-free

* Present address: Karolinska Institutet, Huddinge University Hospital, S-141 86 Huddinge, Sweden. 
oviducal segments from pigs at various stages of the oestrous cycle but in-vitro methods may be considered unphysiological in many respects.

At present the only description of oviducal motility in vivo during the oestrous cycle of the pig is that of Zerobin \& Spörri (1972); measurements of the intraluminal pressure were made with openend catheters which could be obstructed by tubal secretions or mucosal fragments. A further disadvantage was the possibility of distension of the oviducal muscles and distorted recordings.

In the present investigation of spontaneous oviducal motility in vivo during the oestrous cycle, by means of intraluminal pressure microtransducers, special attention was paid to the period when sperm and egg transport are occurring in the oviducts of pigs.

\section{Materials and Methods}

The 17 healthy, mature crossbred gilts (Landrace $\times$ Yorkshire) were from the Department of Obstetrics and Gynaecology; none had been used previously in any experiments. The gilts were housed indoors and checked twice daily for standing oestrus in the presence of a vasectomized boar. The experiments were carried out during the second or later oestrous cycle of the gilts.

Blood samples for determination of the peripheral plasma levels of progesterone and oestradiol$17 \beta$ were withdrawn from an ear vein immediately before anaesthesia on the day oviducal activity was recorded. Hormone analyses were carried out at the Department of Clinical Chemistry by the radioimmunoassay methods described by Boilert, Edqvist, Johansson, Lindberg \& Martinsson (1973) and Bosu, Edqvist, Lindberg, Martinsson \& Johansson (1976).

The recordings were performed in four different phases of the oestrous cycle, i.e. standing oestrus and early, mid- and late-luteal phases (see Table 1).

Table 1. Criteria used for the classification of materials

\begin{tabular}{cllcc}
\hline & & & \multicolumn{2}{c}{ Hormone conc. } \\
\cline { 4 - 5 } Group & Stage of the oestrous cycle & Ovarian appearance & $\begin{array}{c}\text { Progesterone } \\
\text { (nmol/1) }\end{array}$ & $\begin{array}{c}\text { Oestradiol-173 } \\
\text { (pmol/1) }\end{array}$ \\
\hline 1 & Standing oestrus (1-2 days) & Preovulatory follicles & $0 \cdot 2-1 \cdot 9$ & $28-46$ \\
2a & Early luteal (3rd day) & Recently ovulated follicles & $0 \cdot 8-6 \cdot 1$ & $10-21$ \\
2b & Early luteal (4th day) & Developing CL & $6 \cdot 1-25 \cdot 2$ & $21-22$ \\
3 & Mid-luteal (5-10 days) & Well developed CL & $11 \cdot 8-29$ & $19 \cdot 6-23$ \\
4 & Late luteal (11-15 days) & Solid CL & $41 \cdot 6-67 \cdot 2$ & $19-29$ \\
\hline
\end{tabular}

General anaesthesia was induced with a $5 \%$ aqueous solution of thiopentone sodium (Penthotal Sodium: Abbott) injected into a cannulated ear vein and shallowly maintained with halothane (Halothan, Hoechst) and oxygen. The reproductive tract was exposed by a mid-ventral laparotomy and the ovaries and the genital tract were inspected. Catheters equipped with microtransducers (Millar Mikrotip Catheter Pressure Transducer, Millar Instruments Inc., Houston, Texas, U.S.A.) in the tip were used and different calibres of catheter (PC-340-4F and PC-370-7F) were used for particular areas of the oviduct. The catheters were inserted through the oviducal and/or the distal uterine walls, after perforation of the wall with a blunt instrument to avoid bleeding, and located intraluminally at the uterotubal junction, proximal isthmus, ampullary-isthmic junction and midampulla. The catheters were introduced about $2 \mathrm{~cm}$ inside the lumen and kept in position by a 3-0 catgut thread tied to the mesosalpinx. Simultaneous recordings of both oviducts were then made with 2 or 4 recording points.

The transducers were connected through control units to a four-channel polygraph (Model 79C, Grass Instruments Co., Quincy, Massachussets, U.S.A.). After checking the correct function of the 
recording system, the abdominal incision was closed temporarily. A period of equilibration of about $60 \mathrm{~min}$ was allowed and spontaneous contractions were recorded for at least $30 \mathrm{~min}$. The transducers were then removed and the ventral incision closed. The procedure was repeated up to 3 times in individual animals at different phases of the oestrous cycle. Only occasionally were adhesions or other post-operative complications found: animals thus affected were not used for further studies.

Mean values ( \pm s.e.m.) for the frequency, duration and amplitude of tubal contractions were calculated. Comparisons between two groups were performed by means of a 'protected' Student's $t$ test. ANOVA (one-way classification) was used for comparison of more than two means (Steel \& Torrie, 1960). $P$ values of 0.05 or less were considered significant.

\section{Results}

Typical patterns of the spontaneous oviducal motility obtained in different phases of the oestrous cycle are shown in Text-figs 1-6. The quantitative data are summarized in Table 2.

Table 2. Spontaneous motility of various parts of the pig oviduct in vivo

\begin{tabular}{|c|c|c|c|c|c|}
\hline Group & $n$ & Frequency/min & $\begin{array}{l}\text { Duration } \\
\quad(\mathrm{sec})\end{array}$ & $\begin{array}{l}\text { Amplitude } \\
(\mathrm{mmHg})\end{array}$ & Comments \\
\hline \multicolumn{6}{|c|}{ Uterotubal junction } \\
\hline 1 & 5 & $0.78 \pm 0.02$ & $51 \cdot 2 \pm 3 \cdot 4$ & $128 \pm 28 \cdot 4$ & Simple peristaltic/antiperistaltic tonic waves \\
\hline $2 a$ & 3 & $1.08 \pm 0.22$ & $48.7 \pm 0.54$ & $69 \pm 13.9$ & Wavy pattern with simple tonic contractions \\
\hline $2 b$ & 3 & $0.85 \pm 0.31$ & $59 \pm 7 \cdot 8$ & $78 \pm 12 \cdot 7$ & Simple peristaltic tonic contractions \\
\hline \multicolumn{6}{|c|}{ Proximal isthmus } \\
\hline 1 & 11 & $\begin{array}{r}0.72 \pm 0.10^{*} \\
18 \pm 0.94 \ddagger\end{array}$ & $\begin{array}{r}48 \cdot 0 \pm 0.02 \\
3.4 \pm 0.62\end{array}$ & $\begin{array}{r}118.8 \pm 12.7 \\
37.2 \pm 3.63\end{array}$ & $\begin{array}{l}\text { Outbursts superimposed on basal contractions } \\
\text { (peristalsis and antiperistalsis) }\end{array}$ \\
\hline $2 a$ & 4 & $12.7 \pm 1.96$ & $4.6 \pm 0.91$ & $37.5 \pm 7.25$ & Wavy pattern with stable resting pressures \\
\hline $2 b$ & 3 & $\begin{array}{l}0.96 \pm 0.07^{*} \\
17.5 \pm 5.31 \ddagger\end{array}$ & $\begin{array}{r}48 \cdot 6 \pm 5 \cdot 17 \\
3 \cdot 2 \pm 0 \cdot 60\end{array}$ & $\begin{array}{l}86.6 \pm 10.89 \\
36.3 \pm 5 \cdot 17\end{array}$ & $\begin{array}{l}\text { Peristaltic outbursts of increased activity; } \\
\text { basal activity maintained }\end{array}$ \\
\hline 3 & 3 & $1 \cdot 1 \pm 0.05^{*}$ & $44.5 \pm 6.49$ & $59 \cdot 3 \pm 10 \cdot 18$ & $\begin{array}{l}\text { Irregular base-line with small outbursts of } \\
\text { increased activity }\end{array}$ \\
\hline 4 & 3 & $1 \cdot 3 \pm 0 \cdot 10^{*}$ & $37 \cdot 7 \pm 5 \cdot 09$ & $46 \cdot 0 \pm 5 \cdot 31$ & $\begin{array}{l}\text { Irregular base-line with small outbursts of } \\
\text { increased activity }\end{array}$ \\
\hline
\end{tabular}

Ampullary-isthmic junction

\begin{tabular}{|c|c|c|}
\hline 1 & 6 & $\begin{array}{l}0.85 \pm 0.16^{*} \\
25.5 \pm 2.45 \ddagger\end{array}$ \\
\hline $2 \mathrm{a}$ & 3 & $\begin{array}{r}2.1 \pm 0.48 \dagger \\
23.3 \pm 2.99 \ddagger\end{array}$ \\
\hline $2 b$ & 3 & $\begin{array}{r}0.7 \pm 0.21^{*} \\
20.5 \pm 3.19_{+}^{+}\end{array}$ \\
\hline
\end{tabular}

$45.9 \pm 5.84$

$21.5 \pm 0.99$

$25 \cdot 7 \pm 4 \cdot 48$

$9.6 \pm 2 \cdot 23$

$30 \pm 2 \cdot 83$

$11.5 \pm 2.48$
Outbursts superimposed on basal contractions

Wavy, irregular base-line

Outbursts superimposed on basal contractions

\section{Mid-ampulla}

$\begin{array}{lrcrrr}1 & 10 & 0.81 \pm 0.09^{*} & 45.8 \pm 4.81 & 33.3 \pm 8.94 & \text { Outbursts of increased activity } \\ & & 17.8 \pm 1.04 \ddagger & 4.4 \pm 0.49 & 15.0 \pm 3.08 & \text { (peristalsis/antiperistalsis) } \\ 2 \mathrm{a} & 4 & 10.7 \pm 1.88 & 5.5 \pm 0.59 & 10.6 \pm 0.29 & \text { Stable resting pattern } \\ 2 \mathrm{~b} & 3 & 8.3 \pm 0.72 & 7.6 \pm 0.86 & 15.3 \pm 3.02 & \text { Stable resting pattern } \\ 3 & 3 & 13.5 \pm 0.53 & 4.5 \pm 0.10 & 7.0 \pm 0.70 & \text { Stable resting pattern } \\ 4 & 3 & 14.0 \pm 0 & 4.2 \pm 0 & 11.0 \pm 0.47 & \text { Stable resting pattern }\end{array}$

Values are mean \pm s.e.m. for the no. of observations indicated $(n)$.

* Outbursts of increased activity.

+ Waves.

‡ Basal phasic contractions. 
Spontaneous motility of the isthmus and ampulla during the oestrous cycle

Standing oestrus. As shown in Text-fig. 1, during standing oestrus (Group 1), the isthmus and ampulla were very motile. In the isthmus the resting pressure was variable, with strong outbursts of increased activity ( $>100 \mathrm{mmHg}$ amplitude) superimposed on basal contractions of high frequency $(18 / \mathrm{min})$ and a mean amplitude of $37 \mathrm{mmHg}$. The outbursts occurred with a low frequency, lasting for $48 \mathrm{sec}$ on average. The ampulla also showed a variable resting pressure, with phasic long-lasting contractions superimposed on basal activity. The frequency and duration of the phasic contractions were similar to those of the isthmus. The amplitudes of the basal contractions and the outbursts were significantly lower in the ampulla than in the isthmus $(P<0.05)$.

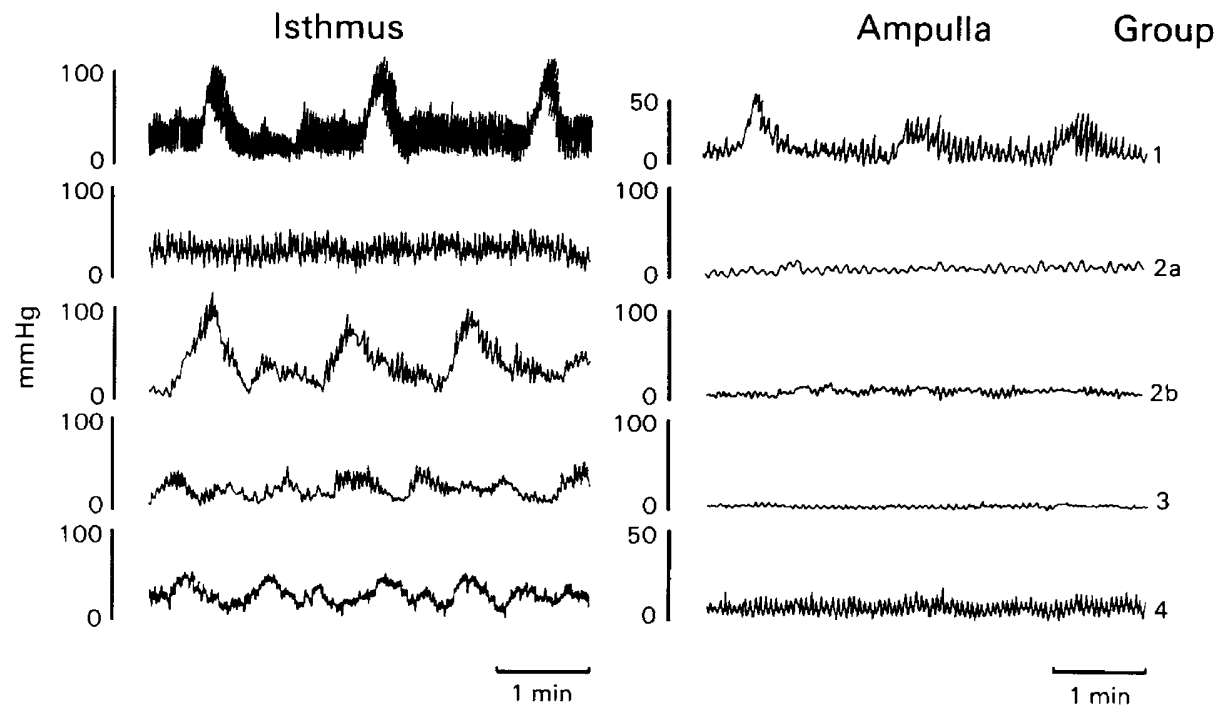

Text-fig. 1. Spontaneous motility of the proximal isthmus and ampulla of the pig oviduct in vivo at different stages of the oestrous cycle (Groups 1-4).

Early luteal phase. Different patterns of isthmic activity appeared on Days 3 and 4 of the cycle. On Day 3 (Group 2a) the wavy pattern with a stable resting pressure was composed of phasic contractions of high frequency $(12 / \mathrm{min})$ and a mean amplitude of $37 \mathrm{mmHg}$. No outbursts of increased activity were recorded. The basal isthmic contractions during Day 3 were almost identical to those recorded during standing oestrus. A stable resting pressure pattern was also present in the ampulla. There were no outbursts of activity. The wavy pattern was composed of phasic contractions of significantly lower frequency $(P<0.01)$ than that of the basal contractions appearing in Group 1 gilts. The amplitude was also decreased $(10 \mathrm{mmHg})$ but did not differ statistically from that of Group 1. On Day 4 (Group 2b) there were no significant changes in the ampulla compared with Group 2a patterns. However, motility in the isthmus changed abruptly: there were strong outbursts of increased activity superimposed on a sustained basal phasic contractility which was similar to that in Groups 1 and $2 \mathrm{a}$. The outbursts of increased activity were similar to those recorded in Group 1, although the amplitude was lower $(86 \mathrm{mmHg})$. When compared to the ampullary contractions during the same period, the frequency and amplitude of the isthmic basal contractions were significantly higher $(P<0.01)$.

Mid-luteal phase. Between Days 5 and 10 of the cycle (Group 3), the isthmus showed variable resting pressures and outbursts of increased activity $(60 \mathrm{mmHg})$ with a frequency of $1-2$ peaks/min. 
No definite basal contractility was present. No significant differences in the frequency and duration of outbursts were found between Groups 1, 2b, 3 and 4. The amplitude was not significantly different from that of Group $2 \mathrm{~b}$, but was lower than that of Group $1(P<0.01)$. The ampulla showed an almost flat pattern with a lower amplitude $(P<0.05)$ and a maintained frequency when compared to Groups 1, 2a and 2b. All characteristics of the pattern differed significantly $(P<0.01)$ from the pattern recorded for the isthmus during the same period.

Late luteal phase. During Days 11-15 of the oestrous cycle (Group 4) the isthmus showed an irregular base line and small outbursts of increased activity $(46 \mathrm{mmHg}$ ). No clear basal activity was seen. There were no significant differences from the patterns in Group 3. The ampulla showed regular phasic motility with a sustained frequency and a significantly higher amplitude $(P<0 \cdot 01)$ than in Group 3, although maintaining stable resting pressures.

Spontaneous oviducal motility recorded at 4 different points during standing oestrus and the early luteal phase

Standing oestrus. During Days 1 and 2 of the cycle, the uterotubal junction showed a pattern of single tonic waves, with small spikes at the top. The tonic waves had a low frequency, long duration and a mean amplitude of $130 \mathrm{mmHg}$ (Text-figs $2 \& 3$ ). Sometimes the tonic waves corresponded to outbursts of increased activity superimposed on basal contractions (Text-fig. 4). The ampullaryisthmic junction showed a more complex pattern with outbursts of low frequency, long duration and mean amplitude of $45 \mathrm{mmHg}$ superimposed on basal contractions of high frequency $(25 / \mathrm{min})$ and lower amplitude $(20 \mathrm{mmHg})$.

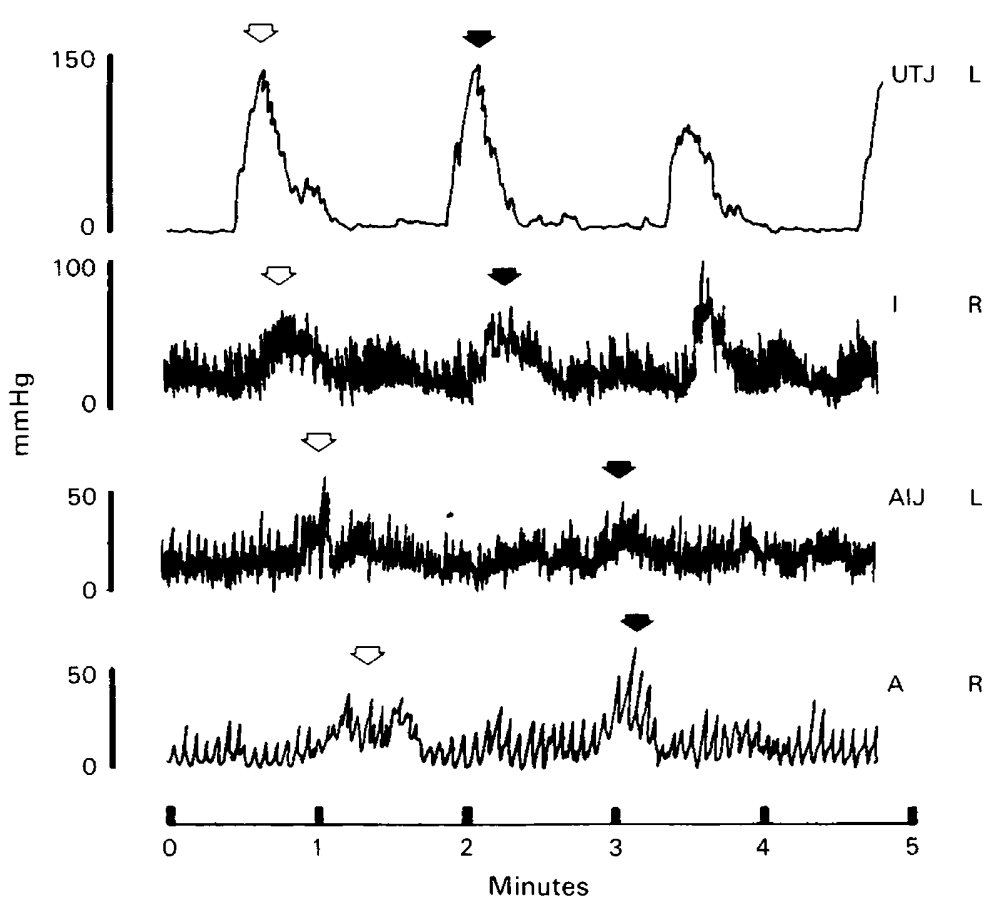

Text-fig. 2. Spontaneous motility of different segments of the pig oviduct on Day 1 of the cycle showing synchronous activity between the left $(L)$ and right $(R)$ sides with antiperistaltic waves progressing from the UTJ to the ampulla (arrows) (UTJ, uterotubal junction; I, proximal isthmus; AIJ, ampullary-isthmic junction; A, ampulla). 


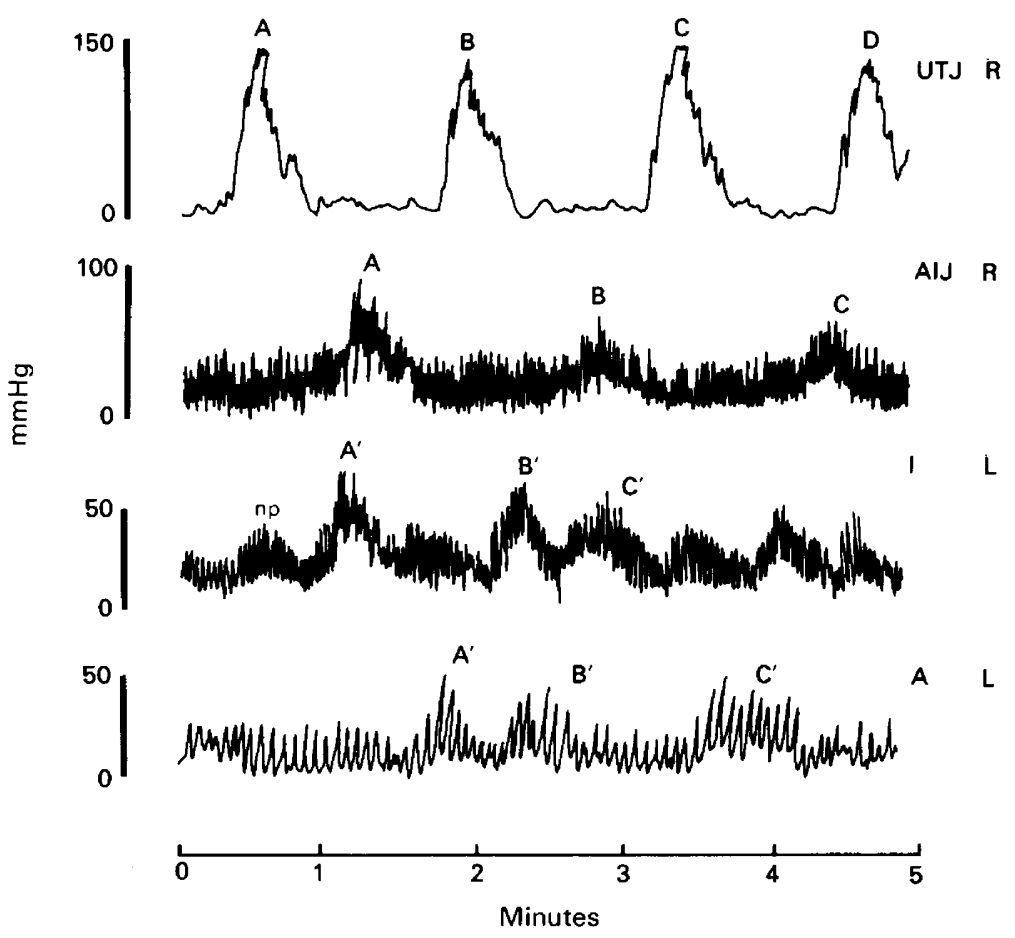

Text-fig. 3. Spontaneous motility of the pig oviduct on Day 1 of the cycle showing nonsynchronous activity between left (L) and right (R) sides. On each side only antiperistaltic waves $(A, B, C)$ and non-propagating waves (np) are seen.

The force developed decreased from the uterine to the ovarian end, corresponding to the decrease in thickness of the muscular coat of the oviduct. There were also single tonic contractions, mainly in the uterotubal junction, while in the other segments these tonic waves were superimposed on basal contractions. No significant differences in frequency of tonic waves were found between segments, but there were differences between basal contractions, which were most frequent $(P<$ 0.05 ) in the ampullary-isthmic junction. No significant differences were found in the duration of waves. Peristalsis and antiperistalsis were seen, as well as non-propagating waves (Text-figs 2-4) on Days 1 and 2 of the cycle. On Day 1 antiperistalsis was mostly seen, with the waves progressing from the uterine to the ovarian pole in all the segments recorded. The remaining waves were peristaltic or non-propagating. The non-propagating waves covered only a segment of the tube. The speed of propagation was $\sim 0.6 \mathrm{~cm} / \mathrm{sec}$. When recordings were made close to the time of ovulation (30-40 h from onset of oestrus), peristaltic and antiperistaltic waves were found in equal numbers (Text-fig. 4) together with some non-propagating waves. The average speed of propagation was $\sim 0.5 \mathrm{~cm} / \mathrm{sec}$.

Early luteal phase. On Days 3-4 the uterotubal junction showed characteristics similar to those at standing oestrus. The ampullary-isthmic junction revealed striking qualitative differences from the pattern during standing oestrus. On Day 3 there was an active pattern but the amplitude of the strong outbursts decreased significantly $(P<0.05)$, as did the basal phasic contractions $(P<0.01)$, appearing now as a wavy pattern with an irregular base-line. The frequency of the waves was statistically different from that of the outbursts appearing in the same segment in standing oestrus $(P<0.05)$. However, the frequency of the basal contractions remained unchanged. The significant differences at this stage $(P<0.01)$ resided mainly in the low activity of the ampulla and the sustained activity of the proximal segments of the tube. These maintained the gradient of developed force that appeared during standing oestrus among oviducal segments. 


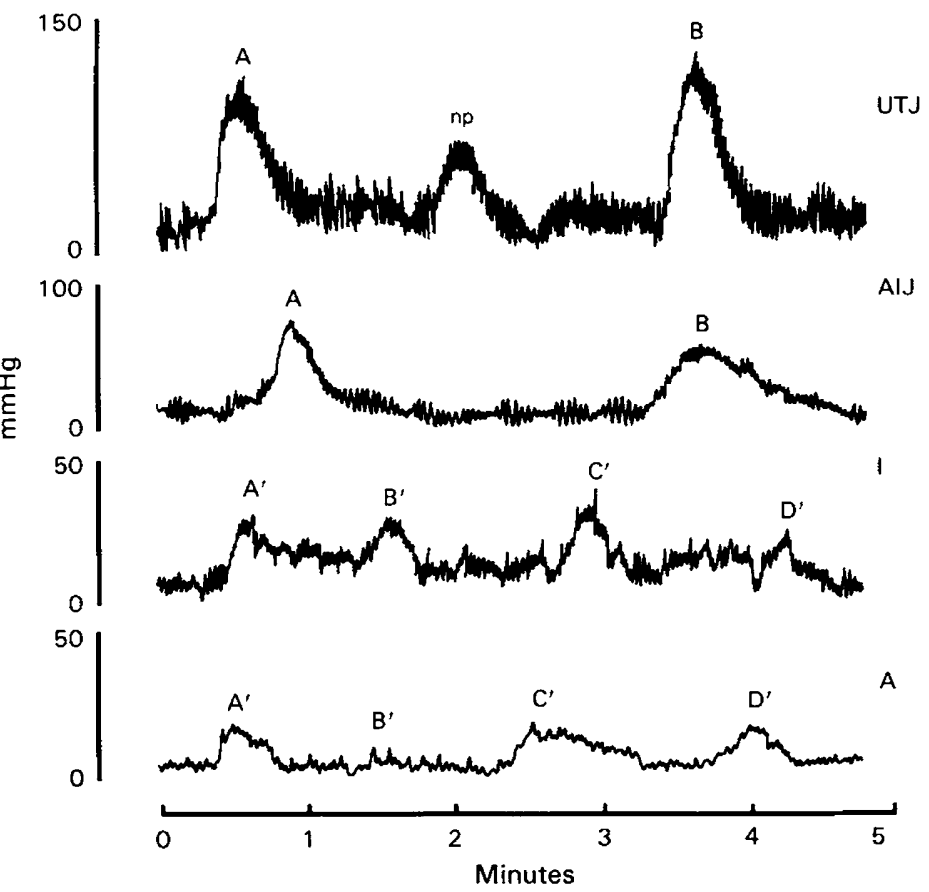

Text-fig. 4. Spontaneous motility of the pig oviduct on Day 2 of the cycle. Recordings were taken simultaneously from the UTJ and AIJ and the isthmus (I) and ampulla (A) but at different intervals in the same oviduct. In the UTJ and AIJ tracings antiperistaltic waves can be seen, while the I and A tracings show peristaltic waves (np, non-propagating wave).

At Day 3 there was no synchrony between the left and right sides and no peristalsis (Text-fig. 5). There was no similarity in shape or time between the strong tonic waves present in the

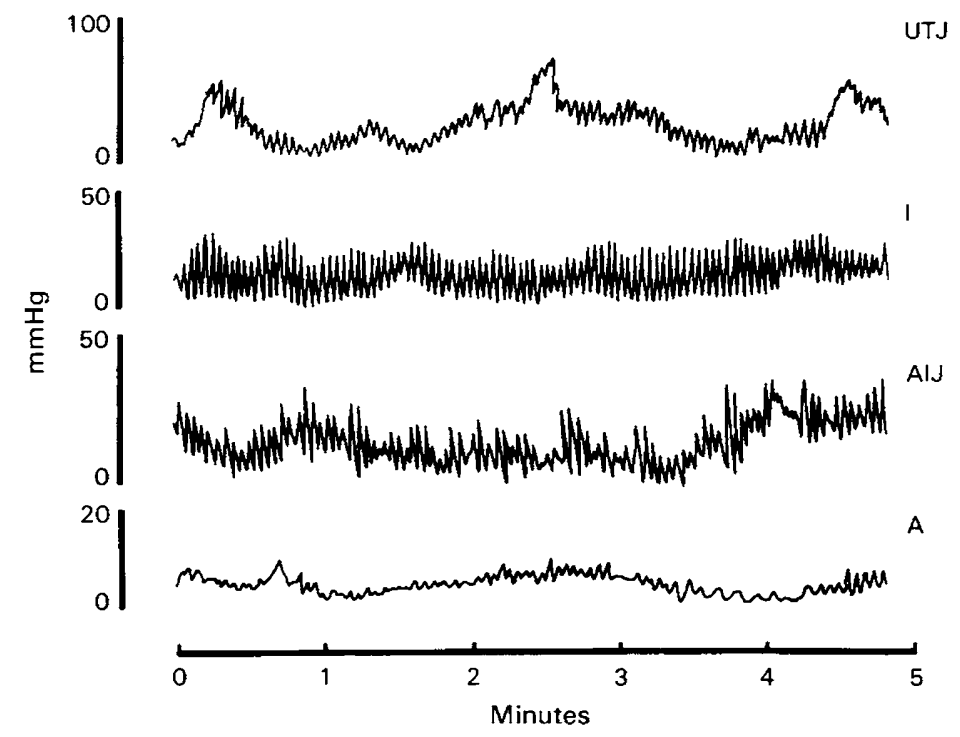

Text-fig. 5. Spontaneous oviducal motility on Day 3 of the cycle. No peristaltic and/or antiperistaltic waves are present. 
uterotubal junction and the waves in the isthmus and ampullary-isthmic junction, or in the ampulla in which there was reduced activity.

During Day 4 the ampullary-isthmic junction pattern was characterized by the reappearance of small outbursts of increased activity $(30 \mathrm{mmHg}$ amplitude) with low frequency and long duration, superimposed on a sustained basal phasic activity. The amplitude values were not significantly different from those in Group 2a (Day 3) but were statistically lower than those in Group 1 ( $P<$ $0.05)$. Significant differences were found between the different segments at this stage $(P<0.01)$ in relation to the changes in motility shown by the ampullary-isthmic junction and isthmus, the sustained activity of the uterotubal junction and the flattened ampullary motility. The isthmus showed the highest developed force of all segments $(86 \mathrm{mmHg})$. Peristalsis was usually observed at this stage, starting in the ampullary-isthmic junction and progressing to the uterotubal junction (Text-fig. 6) with an average speed of $0.5 \mathrm{~cm} / \mathrm{sec}$, i.e. a rate similar to that recorded during standing oestrus.

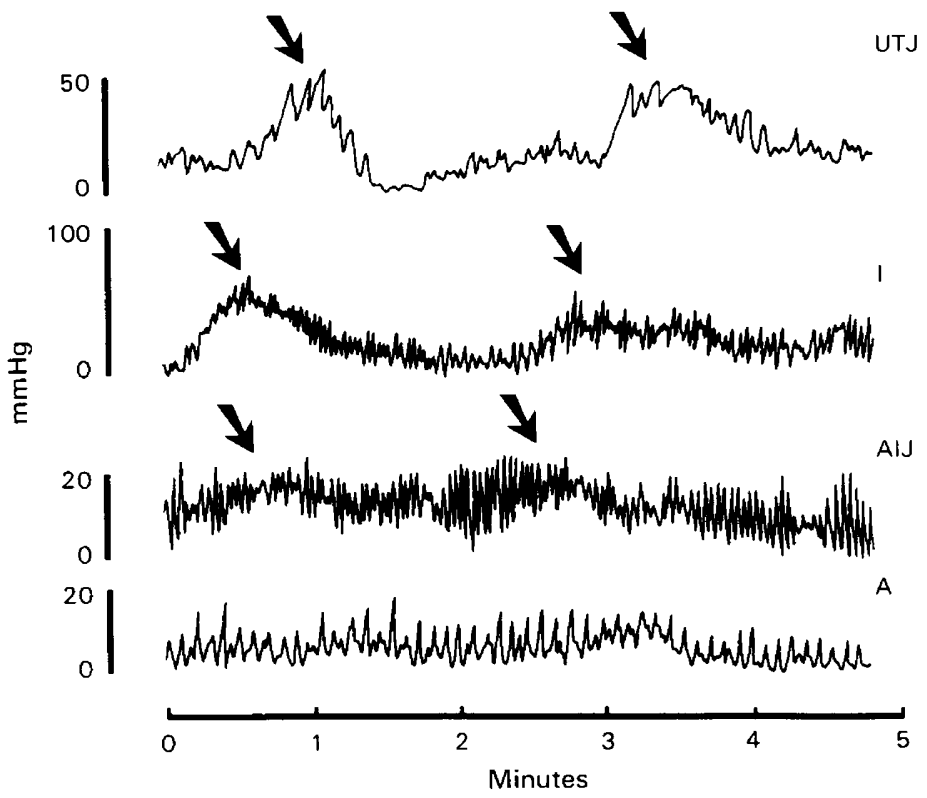

Text-fig. 6. On Day 4 of the cycle peristaltic waves are present, starting at the AIJ and progressing to the uterine side. No waves are present in the ampulla.

\section{Discussion}

All oviducal segments recorded showed definite cyclic changes in their spontaneous contractility during the oestrous cycle stages studied. The uterotubal junction, isthmus and ampullary-isthmic junction showed very strong activity throughout the cycle, while the ampulla showed a similar activity only during the periovulatory period. These findings for the isthmus and the ampulla agree basically with the results from corresponding in-vitro studies, using mesosalpinx-free isolated tubes, covering the same stages of the oestrous cycle (Rodriguez-Martinez et al., 1982). Our results do, however, differ to some extent from those of Zerobin \& Spörri (1972) and the discrepancies are believed to be due to the fact that they employed different recording methods. They concluded that the pig oviduct had no clear-cut spontaneous motility in the mid- and late-luteal phases but we always found an active pattern in the isthmus, with outbursts of up to $60 \mathrm{mmHg}$. 
During Days 1 and 2 of the oestrous cycle Zerobin \& Spörri (1972) demonstrated contractions predominantly in the isthmus, while the ampulla had low activity, but we found sustained motility in all segments with basal phasic contractions and overimposed strong tonic waves being mostly antiperistaltic on Day 1 of oestrus and peristaltic and antiperistaltic in the periovulatory period. Zerobin \& Spörri (1972) mostly recorded antiperistaltic waves during the 2nd day of oestrus. Peristaltic and antiperistaltic waves have been recorded in vivo during the proliferative and early luteal phases in sheep (Wintenberger-Torres, 1961) and women (Maia \& Coutinho, 1970; SicaBlanco, Cibils, Remedio, Rozada \& Gil, 1971). The speed of propagation of the waves in any direction is reduced in women when progesterone concentrations are high (Maia \& Coutinho, 1976). We found no significant differences between the speed of the peristaltic waves during the early luteal phase or during oestrus, despite different levels of circulating progesterone. It is suggested that the spontaneous muscular activity of the pig oviduct during oestrus has the main function of transporting gametes to the fertilization site by means of peristaltic/antiperistaltic waves.

Unlike Zerobin \& Spörri (1972) we found a low ampullary activity during Days 3 and 4 of the oestrous cycle. Strong basal contractions were found in the proximal levels when ova are retained (Alanko, 1974). In the rabbit, temporary constriction of the isthmus occurred when the ova were being retained in the oviduct (Blair \& Beck, 1976). It is suggested that the contraction pattern recorded in the pig isthmus during Day 3 might decrease or perhaps cause complete constriction of the lumen of this oviducal segment. The fact that the contraction pattern of the pig isthmus during the early luteal phase mainly resulted from contractions of the circular muscles (RodriguezMartinez \& Einarsson, 1982) supports this possibility (see Blair \& Beck, 1977).

The appearance of very strong peristaltic waves running from the ampullary-isthmic junction to the uterotubal junction on Day 4 might be responsible for the descent of ova through the isthmus. Similar periods of elevated and depressed activity, corresponding closely in time to the period of periovulatory transport of spermatozoa and slow post-ovulatory transport of ova through the proximal oviducal segments, were recorded in conscious, unrestrained rabbits by means of an intraluminal optoelectronic transducer (Bourdage \& Halbert, 1980).

In the pig the highest levels of circulating oestrogens occur during pro-oestrus, reaching maximum levels before the onset of standing oestrus (Karlbom, Einarsson \& Edqvist, 1982). No significant blood levels of progesterone appear until after ovulation, reaching values of $10 \mathrm{nmol} / \mathrm{l}$ at about Day 4 of the cycle (Karlbom et al., 1982). The strongest oviducal contractions in the pig appeared during oestrus after the sharp drop of oestrogens and might therefore be provoked by oestrogen withdrawal, as suggested for the rabbit (Boling \& Blandau, 1971) or due to a phase difference between the concentrations of steroids in the plasma and in the target tissues.

Prostaglandins affect the pattern of oviducal motility in the pig, both in vitro and in vivo $(\mathrm{H}$. Rodriguez-Martinez, unpublished results) and high concentrations of PGF- $2 \alpha$ are present in the oviducal fluid during oestrus (unpublished results). Saksena \& Harper (1975) reported an increase of PGF in rabbit oviducal tissue after treatment with oestradiol. A relationship may therefore exist between the high oestradiol levels in blood, the appearance of PGF- $2 \alpha$ in the oviducal fluid and the motility pattern of the pig oviduct during standing oestrus.

The occurrence of strong peristaltic waves during the 4th day of the oestrous cycle coincides with increasing progesterone concentrations as well as with the levels of the main metabolite of PGF-2 $\alpha$ in the peripheral circulation (Shille et al., 1979). It is therefore probable that the cyclic activity of the oviducal musculature of the pig is regulated by these hormones.

We thank Eva Hedberg, Marie Wallbring and Marianne Carlsson for help; the Swedish Institute for a scholarship (H.R.M.); and the Centro de Investigaciones Veterinarias "M. C. Rubino" (M.A.P.) and Facultad de Medicina (U.M.R.), Uruguay, for granting study leave for H.R.M. Supported by the Swedish Council for Forestry and Agricultural Research. 


\section{References}

Alanko, M. (1974) Fertilization and early development of ova in AI gilts, with special reference to the role of tubal sperm concentration: a clinical and experimental study. $\mathrm{Ph} . \mathrm{D}$. thesis, Helsinki.

Blair, W. \& Beck, L. (1976) Demonstration of postovulatory sphincter action by the isthmus of the rabbit oviduct. Fert. Steril. 27, 431-441.

Blair, W. \& Beck, L. (1977) In-vivo effects of prostaglandins $F_{2} \alpha$ and $E_{2}$ on contractility and diameter of rabbit oviduct using intraluminal transducers. Biol. Reprod. 16, 122-127.

Blandau, R. \& Gaddum-Rosse, P. (1974) Mechanism of sperm transport in pig oviducts. Fert. Steril. 25, 6167.

Blandau, R., Brackett, B., Brenner, R., Boling, J., Broderson, S., Hamner, C. \& Mastroianni, L. (1977) The oviduct. In Frontiers in Reproduction and Fertility Control: A Review of the Reproductive Sciences and Contraceptive Development, part II, pp. 132-145. Eds R. Greep \& M. Koblinsky. MIT Press, Cambridge, Massachusetts.

Boilert, B., Edqvist, L., Johansson, E., Lindberg, P. \& Martinsson, K. (1973) The influence of conjugated estrogens in radioimmunoassay using different antibodies against estradiol-17 3 . Steroids 22, 891-900.

Boling, J.L. \& Blandau, R.J. (1971) The role of estrogens in egg transport through the ampullae of oviducts in castrate rabbits. Fert. Steril. 22, 544-551.

Borda, E., Speziale, N., Borda, L., Gimeno, M. \& Gimeno, A. (1980) Contractile characteristics of fimbrial, isthmic, ampullar and fimbrio-ampullar segments of isolated sow (Sus scrofa) oviducts as influenced by ovulation, adrenergic mechanisms and prostaglandin $\mathrm{E}_{1}$. Int. J. Fertil. 25, 28-35.

Bosu, W., Edqvist, L., Lindberg, P., Martinsson, K. \& Johansson, E. (1976) The effect of various dosages of lynesterol on the plasma levels of estrogens and progesterone during the menstrual cycle in the Rhesus monkey. Contraception 13, 677-684.

Bourdage, R. \& Halbert, S. (1980) In-vivo recordings of oviductal contractions in rabbits during the periovulatory period. Am. J. Physiol. 239, 332-336.

Einarsson, S. \& Viring, S. (1973) Effect of boar seminal plasma on the porcine uterus and the isthmus part of the oviducts in vitro. Acta vet. scand. 14, 639-641.
Karlbom, I., Einarsson, S. \& Edqvist, L. (1982) Attainment of puberty in female pigs: clinical appearance and patterns of progesterone, estradiol 17-beta and LH. Anim. Reprod. Sci. 4, 301-312.

Maia, H. \& Coutinho, E. (1970) Peristalsis and antiperistalsis of the human Fallopian tube during the menstrual cycle. Biol. Reprod. 2, 305-314.

Maia, H. \& Coutinho, E. (1976) Motility of the human oviduct in vivo. In Ovum Transport and Fertility Regulation, pp. 221-227. Eds M. J. K. Harper, C. J. Pauerstein, C. E. Adams, E. M. Coutinho, H. B. Croxatto \& D. M. Paton. Scriptor, Copenhagen.

Rodriguez-Martinez, H. \& Einarsson, S. (1982) Spontaneous contractility of isolated muscle layers of the pig oviductal isthmus. Acta physiol. scand. 115, 325-330.

Rodriguez-Martinez, H., Einarsson, S., Larsson, B., Akusu, M. \& Settergren, I. (1982) Spontaneous motility of the pig oviduct in vitro. Biol. Reprod. 26, 98-104.

Saksena, S. \& Harper, M. (1975) Relationship between concentration of prostaglandin $F$ (PGF) in the oviduct and egg transport of rabbits. Biol. Reprod. 13, 68-76.

Shille, V., Karlbom, I., Einarsson, S., Larsson, K., Kindahl, H. \& Edqvist, L. (1979) Concentrations of progesterone and 15-keto-13-14-dihydroprostaglandin $\mathrm{F}_{2} \alpha$ in peripheral plasma during the estrous cycle and early pregnancy in gilts. Zentbl. Vet. Med. 26, 169-181.

Sica-Blanco, Y., Cibils, L., Remedio, M., Rozada, H. \& Gil, B. (1971) Isthmic and ampullar contractility of the human oviduct in vivo. Am. J. Obstet. Gynec. 111, 91-97.

Steel, R. \& Torrie, J. (1960) Principles and Procedures of Statistics. McGraw-Hill, New York.

Viring, S. (1981) Studies on the sperm transport in the genital tract of the gilt. Ph.D. thesis, Uppsala.

Wintenberger-Torres, S. (1961) Movements des trompes et progresion des oeufs chez la brébis. Annls Biol. anim. Biochim: Biophys. 1, 121-133.

Zerobin, K. \& Spörri, H. (1972) Motility of the bovine and porcine uterus and Fallopian tube. Adv. Vet. Sci. Comp. Med. 16, 303-354.

Received 1 March 1982 